А. А. Баркович

\title{
ИДЕНТИЧНОСТЬ РЕЧЕВОЙ ПРАКТИКИ В КОНТЕКСТЕ КОМПЬЮТЕРНО-ОПОСРЕДОВАННОЙ КОММУНИКАЦИИ
}

Баркович О. А. Ідентичність мовленнєвої практики в контексті комп'ютерноопосередкованої комунікації.

Стаття присвячена проблематиці ідентичності мовної практики в контексті комп'ютерно-опосередкованої комунікації. Синкретизм технічних і гуманітарних знань нової лінгвоінформаційної якості, розширені можливості розгляду сучасного мовленнєвого процесу в контексті соціальних і ментальних, психологічних особливостей комунікаційної діяльності людини створює передумови для метаописів функціонування різних варіантів мови.

Ключові слова: комп'ютерно-опосередкована комунікація, комп'ютерноопосередкована дискурс, лінгвоінформаційність, метаформат, ідентичність, культуролект, феномен.

Баркович А. А. Идентичность речевой практики в контексте компьютерноопосредованной коммуникации.

Статья посвящена проблематике идентичности речевой практики в контексте компьютерно-опосредованной коммуникации. Синкретизм технических и гуманитарных знаний нового лингвоинформационного качества, расширенные возможности рассмотрения современного речевого процесса в контексте социальных и ментальных, психологических особенностей коммуникационной деятельности человека создает предпосылки для метаописаний функционирования различных вариантов языка.

Ключевые слова: компьютерно-опосредованная коммуникация, компьютерноопосредованный дискурс, лингвоинформационность, метаформат, идентичность, культуролект, феномен.

Barkovich A. A. Identity of speech practice in the context of computer-mediated communication.

The article deals with the problem of identity of speech practice in the context of computer-mediated communication. Syncretism of technical and humanitarian knowledge of new linguoinformational quality, advanced capabilities of review of modern speech process in the context of social and mental, psychological characteristics of the human С А. А. Баркович, 2015. 


\section{СТРУКТУРА І СЕМАНТИКА МОВНИХ ОДИНИЦЬ}

communicational activity creates the preconditions for meta descriptions of the functioning of language various options.

Key words: computer-mediated communication, computer-mediated discourse, linguoinformationality, metaformat, identity, culturalist, phenomenon.

Язык, будучи системообразующим фактором социокультурной сферы, в среде компьютерно-опосредованной коммуникации (далее КОК) сам чрезвычайно уязвим и восприимчив к разного рода влияниям. Характерным феноменом, приметой времени, является «открытость» в сфере КОК лексических систем языков, которые ничем не защищены в условиях, например, экспансии заимствований [1]. Неконтролируемое проникновение в славянские языки - как и во многие другие - массы заимствований, агнонимов, «экзотизмов», в том числе, из сферы КОК особенно заметно в интернет-дискурсе. Препятствием для такого проникновения не становятся огромные, особенно в синтетических языках, к которым относятся и славянские, внутренние резервы языка: неисчерпаемые ресурсы потенциальных слов, разнообразные словообразовательные и деривационные возможности исконной лексики.

Поликодовость, интерференция и диффузия лингвистического содержания языковых данных сферы КОК обусловливают своеобразный метаформат их функционирования. В метаформате КОК - обобщенном представлении о структуре и сущности феномена - органично сочетаются и лингвоинформационный, и коммуникационный, и дискурсивный, и сетевой, и речевой и другие признаки ее функциональности. Реализациями такой форматности являются не только отдельные «электронные» тексты компьютерно-опосредованного дискурса (далее - КОД) и сайты Интернета, но и сложные структуры вроде лингвистических корпусов и социальных сетей. Компьютерное опосредование среды речевой практики обусловливает непривычную по сравнению с традиционным дискурсом спаянность и интерактивность единиц дискурса, функциональную обусловленность субъектных и объектных характеристик КОК.

В контексте высокой динамики речевой практики КОК особую актуальность приобретают идентичные черты того или иного дискурса. Такая идентичность востребована не только в контексте тотальной формализации естественноязыковых систем и их адаптации к логике компьютерного представления семантики, но и - в контексте значимого влияния КОД на развитие всей сферы речевого функционирования. Идентичность сферы современного речевого функционирования может быть рассмотрена в нескольких аспектах: гуманитарно-технологической 
специфики; индивидуально-социальной специфики; интралингвистическиэкстралингвистической специфики; специфики межъязыкового взаимодействия и др.

Рассмотрение речевой практики в контексте КОК - потенциально чрезвычайно наукоемкая проблемная область. Будучи в значительной степени обусловленной технологической (компьютерной) опосредованностью сферы КОК, сама речевая деятельность сферы КОК несомненно обусловлена лингвистической парадигматикой, без которой исследование проблемной области лишено смысла. Интердисииплинарный характер сферы КОК обусловливает комплексный подход как к формированию ее целостного метаязыкового описания, так и при выполнении частных исследований определенной локализации [2]. Синкретизм технических и гуманитарных знаний нового компьютерноопосредованного качества, объективная необходимость рассмотрения современного процесса речи в контексте социальных и ментальных, психологических условий существования личности человека - с неизбежностью приводит к осознанию интерактивного характера задействования различных вариантов и форм реализации языка. Подобная полиформатность в сфере КОК существует как объективная реальность, будучи актуальной как в общенаучном контексте когнитивной деятельности, так и в контексте лингвистической, собственно, мультидисциплинарности.

В среде КОК высокая структурированность и категориальность метаязыковых описаний обеспечивают особую «прозрачность» процесса развития языковой системы: КОД сохраняется как серия фотографий, позволяя анализировать динамику развития речи. В условиях стратифицированности и кластеризованности текстов КОД метаязыковые описания сферы КОК - не только основание, но и важный иллюстративный и объяснительный ресурс, который обеспечивает корреляцию практики исследования языка с лингвистической теорией.

Очевидным объектом лингвистического описания речевой деятельности в контексте КОК представляется изучение ее индивидуальносоциальной специфики. В дискурсивной методологии подобный вектор исследования структурирован по признаку персональности / институциональности дискурса. С учетом данной категоризации, целесообразным представляется рассмотрение феноменологической специфики, субъектно-объектных особенностей КОД.

В данном аспекте существенным системным потенциалом обладает дифференциация ключевых элементов, объектов идентичности речи КОК на макроуровне, таких, например, как идиолект и соииолект. При () А. А. Баркович, 2015. 
внимательном рассмотрении оказывается, что богатство речевой практики не ограничено только данной диадой. Для лингвиста КОД представляет обширнейший материал, релевантный в плане разных вариантов языка идиолектов, сочиолектов, культуролектов, криптолектов, узуалектов и т. д. Так, социолект как реализация сочиальнообусловленной языковой идентичности, например, участников тематического «чата», зачастую представляет собой упрощенный вариант языка, нередко нарочито примитивный. КОД, как правило, характеризуется высокой степенью спонтанности и аутентичности текстов, минимальностью дистанции между мышлением и написанием или озвучиванием продукции мышления.

По индивидуальным особенностям речи коммуникационные персонажи блогов и социальных групп почти безошибочно идентифицируются другими участниками коммуникации [4]. Это происходит, в том числе, благодаря идиолектичности речи. Аналитические выводы о личности собеседника во многом строятся на косвенных, опосредованных данных, доступных из коммуникационного акта или деятельности в целом. Посредником выступает проекция языка и ментальной деятельности в материальном мире - речь. КОД при отсутствии сведений о собеседнике, полученных напрямую от органов чувств, воспринимается намного острее и основательней, чем «обычная» речевая деятельность, которая сопровождается визуальным или слуховым контактом с собеседником.

Идиолект складывается в определенных социальных и культурных условиях, являясь стабильным набором характерных языковых черт, в том числе, в контексте КОК. Это индивидуальная идентичность четко воспринимается собеседниками, особенно если коммуникационная личность под разными масками использует или создает, например, флуд, троллинг, флэйм и т. д. Безусловно, для филологов такие проявления более заметны, чем для других наблюдателей и участников коммуникации.

Традиционно большинство вариантов необычного использования языковых средств зарождается и тестируется в разговорном языке. Здесь языковая практика далека от письменной формы и обладает широчайшей вариативностью, от узуализма до контекстуализма. Не все случаи нестандартного словоупотребления носят демонстративный и умышленный характер. Хотя в просторечии случаи отклонения от нормы могут являться следствием плохого владения языком, что выражается в креолизованных формах речи. В случае с близкородственными восточнославянскими языками - это «трасянка» в Беларуси и «суржик» в Украине. Появление КОК стало настолько значимым глобальным социокультурным событием, 
что в контексте «великого переселения языков» в Интернет (КОК) вновь актуализировались такие казалось бы давно забытые исторические реалии языковой идентичности, как креольские языки и пиджины.

Вряд ли оправдано отнесение таких реализаций языковой «материи» как трасянка, суржик и под. к социолекту, скорее, следует их квалифицировать как культуролект - обобщенную форму языковой идентичности, обусловленную культурной спецификой социума. Подобная модель языковой идентичности может актуализироваться как атрибут субкультуры, однако понятийная определенность и гуманитарная значимость культуролекта являются вполне самодостаточными, являясь основаниями для широкой имплементации данного термина для филологически-релевантных метаописаний языка.

К понятию культуролекта близко подошел известный американский исследователь Джон Гамперц, отмечая, что переключение кодов возможно не только на межъязыковом уровне, но и на уровне диалекта и стиля. Синхроннические корреляты языка, «...субкоды одного и того же языка в пределах кодовой матрицы также проявляют несколько степеней языковых различий. В языковом отношении местные диалекты могут отличаться или быть очень похожими на официальные формы речи. То же справедливо и относительно стилей» [10]. При изучении стилистически выразительных текстовых и дискурсивных совокупностей того или иного варианта языка его идентификация как коммуникационного феномена обладает большим лингвистическим потенциалом.

Вся гамма вариативности языка отражается в КОК, предоставляя коммуникационной личности как субъекту речевой идентичности КОК широчайшие возможности для реализации, идентификации и взаимодействия.

Можно констатировать, что язык как социокультурный феномен и средство реализации идентичности успешно преодолел «барьер» КОК (Интернета). В КОК большинство языков устойчиво функционирует и развивается, адаптируется к новым реалиям, изменяется и приспосабливается. Так, например, поисковые сервисы Интернета по наиболее популярным запросам ищут ответы в более, чем 20000000 миллионах белорусскоязычных текстов. Конечно же, статистика, да и принципы определения белорусскоязычной идентичности того или иного фрагмента интернет-гипертекста могут обсуждаться, но порядок цифр убедительно свидетельствует о «дееспособности» белорусскоязычного КОД.

При этом, если сфера функционирования языка характеризовалась противоречиями до «эпохи Интернета», в сфере КОК проблемы речи не (ㄱ А. А. Баркович, 2015. 
решились автоматически. Так, сфера функционирования белорусского языка, не будучи господствующей на территории современной Беларуси во времена СССР - можно говорить, скорее, о паритете с русским языком, - с обретением республикой независимости значительно сузилась. Более того, существовавшие в белорусском языке исторические влияния таких факультативных форм реализации языковой идентичности, как «тарашкевица» (форма языка, закрепленная в нормах «Белорусской граммматики для школ», изданной Брониславом Тарашкевичем в 1918 г.) и «латинка» (транслитерации письменной речи латинскими буквами - форма письменной речи), в условиях демократизации социума получили возможность стать существенными экстралингвистическими факторами. На практике они дезориентировали, в определенном смысле, сферу культуры и образовательную сферу. Можно предположить, что наличие нескольких параллельных форм и вариантов белорусскоязычной идентичности, безусловно, подтолкнуло значительную часть жителей Беларуси к английскому, польскому и, естественно, русскому языкам.

Интересные подробности совместного существования вариантов белорусского языка содержит «Википедия»: на 17 октября 2013 г. здесь присутствовало 64763 статьи на нормативном белорусском языке и 50848 статей на «тарашкевице» [5]. При этом, статьи «Википедии» про одно и то же на разных языках часто существенно отличаются, дублируется, к сожалению, и тематика многих статей на белорусском литературном языке и «тарашкевице» в «Википедии». Очевидно, что «Байнет» (белорусскоязычный Интернет), как и белорусская культура в целом, используя единую форму идентичности языка, могли бы быть вдвое богаче.

Влияние разных форм языковой идентичности на функциональность языковой системы в контексте компьютерноопосредованной речевой практики проявляется контрастно и приобретают новые феноменологические характеристики. Так, например, трасянка в Беларуси, которая была достаточно широко распространена и до появления Всемирной паутины, получила гораздо больше возможностей для фиксации в сфере КОК. Благодаря подобной речевой «легализации» - маргинальной по существу языковой идентичности трасянка даже перестала восприниматься как необразованность и стала привычным атрибутом речевой практики. Показательной в этой связи является социолингвистическая статистика открытого опроса в Беларуси: «...проведенный в 2008 году иностранными учеными опрос в семи городах страны показал, что более трети (37,6\%) белорусов-горожан считают своим родным языком трасянку (48,6\% назвали в качестве такового 
белорусский и 29,6\% - русский язык). 43,4\% респондентов в повседневной практике используют преимущественно русский язык с примесью белорусских слов; 41,0\% используют смешанный язык, 11,2\% стандартный русский. Стандартный белорусский или белорусский с добавлением русских слов используют все вместе 4,4\%. При сравнении разных поколений у самых молодых респондентов происходит некоторое перераспределение предпочтений от смешанного языка $(33,4 \%)$ в пользу русского языка с примесью белорусских слов (50,2\%)» [7]. Надо полагать, что к 2015 г. ситуация принципиально не изменилась.

Разумеется, проблемы с интернационализацией и «интернетизацией» сферы культуры касаются всех языков, в том числе, большинства европейских [6]. Данные интернет-траффика подтверждают, что английский язык безоговорочно лидирует в КОК - более 54,7 \% КОД (на втором и третьем местах - с показателями в 5,9\% - русский и немецкий языки) [11]. Для использующих «нелатинскую» графику языков ситуация осложняется еще и фактором глобального господства в КОК латинской графики, в том числе, англоязычной, которая используется в интерфейсах, браузерах и т. д., став «уникодом» не только для многих славянских исторически кириллических языков, но и активно внедряясь в дискурс на основе китайской, арабской и др. графики.

Использование латиницы во многих «нелатинских» языках стало обычной практикой письменной речи и ее компьютерно-опосредованной разновидности, влияя на графическую идентичность разных языков. Чаще всего, - это вполне безобидное хобби, которое, конечно, противоречит нормам кодифицированного варианта языка. Однако, если латинизация становится инструментом политики - последствия для социокультурной сферы могут быть достаточно серьезными, затрагивающими традиционные устои социума. В качестве примера можно привести так называемый «балканский синдром», когда фактически один язык (еще относительно недавно он был сербскохорватским) политики смогли разделить на сербский, хорватский, боснийский и черногорский.

В данной ситуации одним из ключевых факторов разъединения стабильной культурной сплоченности народов бывшей Югославии стал переход «новых» языков на латинскую графику. Так в Хорватии, значительную часть населения которой составляют сербы, вопрос использования графики стал культурной доминантой: «Протесты, связанные с разрешением или запретом на использование кириллицы, в Вуковаре регулярно вспыхивают с 2011 года. Именно тогда правительство впервые решило к табличкам на хорватском (латиницей) добавить указатели на () А. А. Баркович, 2015. 
сербском (кириллицей)» [8]. Латиница, появившись в Сербии в XIX в., стала активно завоевывать популярность благодаря широкому распространению КОК. Более того, латиница стала существенным фактором социокультурной сферы и в самой Сербии, традиционно «кириллической» стране «... онлайнкоммуникация способствует тому, что сербы вынуждены писать на латинице. Этот алфавит понятен европейцам, и его использование сближает Сербию с ЕС, куда Белград активно стремится в последнее время» [8].

Обстоятельства функционирования речи в КОК обладают существенной спецификой, позволяющей рассматривать тип используемой графики как значимый аргумент в пользу того или иного пути развития современной языковой практики в поликодовой среде КОД. Об устойчивости кириллической традиции говорит высокая деривационная активность как белорусского, так и украинского, русского и др. славянских языков. Например, для ассимиляции понятийной и терминологической базы сферы КОК активно используются внутриязыковые ресурсы славянских языков: ни экспонент Web, ни - Internet не закрепились в славянских языках. Результатом калькирования лексемы Web (World Wide Web) в восточнославянских языках стали такие номинации как Сусветнае павуцінне (в белорусском языке), Всемирная паутина (по-русски), Всесвітня мережа или Всесвітнє павутиння (по-украински). Их широкая представленность в Интернете оказывает ощутимое влияние на развитие и идентичность сферы КОК. Как и в белорусском языке, где активно используется не только Сусветнае павуцінне, но и Сеціва, в русском языке вместо словосочетания Всемирная паутина можно часто встретить Cеть, в украинском языке, кроме словосочетаний Всесвітня мережа и Всесвітнє павутиння, используются Мережа, Тенета, Міжмережжя, Всемережжя [3].

Взаимодействие языков в сфере КОК характеризуется интенсивностью. Данные развития речевой практики Интернета четко свидетельствуют о противоречивости и динамичности взаимодействия различных интра- и экстралингвистических факторов коммуникационной деятельности. Мнение, что интернет-дискурс становится наиболее активным сегментом речевой практики, подтверждается его высокой речевой инновационностью [9]. Комплексный анализ и структурирование метаязыковых особенностей КОД позволяет решить целый ряд вопросов: от идентификации субъективных нюансов речи до многоуровневого моделирования объективной имплементации дискурса. Системной репрезентации проблемной области в таком аспекте практически нет ни в зарубежном, ни в отечественном языкознании. Если это случится, безусловно, мы узнаем о новых свершениях по созданию искусственного 
интеллекта, коммуникационных сетей нового поколения и решении других важных научных задач.

Таким образом, идентичность языковой системы в КОК обусловлена перманентным воздействием широкого круга факторов, в том числе мета- и полиформатностью речевой практики. Подобная ситуация характеризуется повышенной адаптивностью речевой практики при формировании и реализации дискурсивных стратегий. Лингвистический контекст КОК обусловлен сложным интерактивным взаимодействием разнонаправленных векторов или гиперстратегий развития сферы, среди которых определяющими являются, с одной стороны, технологические, а с другой, гуманитарные, в частности, личностные, прагматические и социальные составляющие контекста. Имеются предпосылки для констатации высокой идентичности КОД как уникального сформировавшегося феномена социокультурной сферы. Специфика КОК в контексте лингвистической парадигмы обладает существенным потенциалом структуризации и категоризации, что, несомненно будет востребовано для объективной репрезентации дискурсивной практики как отдельных языков, так и языковой общности сферы КОК.

\section{Литература}

1. Баркович А. А. Интернет-дискурс: компьютерно-опосредованная коммуникация / А. А. Баркович. - М. : Флинта : Наука, 2015. - 288 с.

2. Барковіч А. А. Інтэрдысцыплінарнасць прыкладной лінгвістыкі : філалагічная кампетэнцыя і практычная дзейнасць / А. А. Барковіч // Вестник МГЛУ. Сер. 1. Филология. - 2013. - № 6 (67). - С. 126-134.

3. Барковіч А. А. Сусветнае павуцінне, Сеціва, Вэб і Інтэрнэт у камп'ютарнаапасродкаванай камунікацыі / А. А. Барковіч // Веснік Мазырскага дзяржаўнага педагагічнага ўніверсітэта імя І. П. Шамякіна. - 2014. - № 2 (43). - С. 84-90.

4. Баркович А. А. Феноменологическая характеристика коммуникационной личности компьютерно-опосредованного дискурса / А. А. Баркович // Вестник Брянского государственного университета. - №2 (2015) - С. 85-93.

5. Википедия [Электронный ресурс]. - Режим доступа : http://be.wikipedia.org

6. Дейк ван Т. Язык. Познание. Коммуникация. Сборник работ / Т. ван Дейк. - М. : Прогресс, 1989. - 312 с.

7. Листопадов В. Эксперты : Трасянка может стать вторым основным языком белорусов / В. Листопадов // News.tut.by. 17 декабря 2013 г. [Электронный ресурс]. Режим доступа : http://news.tut.by/society

8. Мельникова К. Языковой барьер - Кириллица стала камнем преткновения в отношениях сербов и хорватов / К. Мельникова // Lenta.ru. 28 августа 2015 [Электронный ресурс]. - Режим доступа : http://lenta.ru

9. Brewington B. How dynamic is the Web? / Brian Brewington and George Cybenko // Computer Networks : The International Journal of Computer and Telecommunications Networking. 2000. - Volume 33, Issue 1-6. - P. 257-276. 
10. Gumperz J. Types of Linguistic Communities / John J. Gumperz // Anthropological Linguistics. - Volume 4, Number 1 (Jan., 1962). - P. 28-40.

11. W3Techs - extensive and reliable web technology surveys [Electronic resourse]. URL : http://w3techs.com

Стаття надійшла до редакиії 31.08.2015 p. 